University of Nebraska - Lincoln

DigitalCommons@University of Nebraska - Lincoln

Publications from USDA-ARS / UNL Faculty

U.S. Department of Agriculture: Agricultural

Research Service, Lincoln, Nebraska

2013

Adoption of site-specific variable rate sprinkler irrigation systems

Robert G. Evans

USDA-Agricultural Research Service, Robert.Evans@ars.usda.gov

Jake LaRue

Valmont Industries, Inc., jlarue@valmont.com

Kenneth C. Stone

USDA-Agricultural Research Service, ken.stone@ars.usda.gov

Bradley A. King

USDA-Agricultural Research Service, Brad.King@ars.usda.gov

Follow this and additional works at: https://digitalcommons.unl.edu/usdaarsfacpub

Evans, Robert G.; LaRue, Jake; Stone, Kenneth C.; and King, Bradley A., "Adoption of site-specific variable rate sprinkler irrigation systems" (2013). Publications from USDA-ARS / UNL Faculty. 1245.

https://digitalcommons.unl.edu/usdaarsfacpub/1245

This Article is brought to you for free and open access by the U.S. Department of Agriculture: Agricultural Research Service, Lincoln, Nebraska at DigitalCommons@University of Nebraska - Lincoln. It has been accepted for inclusion in Publications from USDA-ARS / UNL Faculty by an authorized administrator of DigitalCommons@University of Nebraska - Lincoln. 


\title{
Adoption of site-specific variable rate sprinkler irrigation systems
}

\author{
Robert G. Evans • Jake LaRue $\cdot$ Kenneth C. Stone • \\ Bradley A. King
}

This article is a U.S. government work, and is not subject to copyright in the United States.

Received: 9 March 2012 / Accepted: 22 June 2012 / Published online: 14 July 2012

(C) Springer-Verlag (outside the USA) 2012

\begin{abstract}
More than 20 years of private and public research on site-specific variable rate sprinkler irrigation (SS-VRI) technology on self-propelled center pivot and linear move irrigation systems has resulted in limited commercial adoption of the technology. Competing patents, liability, and proprietary software have affected industry's willingness to move into a new technology area. Documented and proven water conservation strategies using sitespecific irrigation are quite limited. Marginal costs associated with site-specific technologies are high. Although sales of SS-VRI are increasing, they are primarily being used for
\end{abstract}

Communicated by J. Kijne.

Mention of trade names, companies, or commercial products in this publication is solely for the purpose of providing specific information and does not imply recommendation or endorsement by the U.S. Department of Agriculture.

R. G. Evans $(\bowtie)$

USDA-Agricultural Research Service, 1500 N. Central Avenue, Sidney, MT 59270, USA

e-mail: Robert.Evans@ars.usda.gov

J. LaRue

Applications and Project Support, Valmont Industries, Inc., P.O Box 358, Valley, NE 68064, USA

e-mail: jlarue@valmont.com

K. C. Stone

USDA-Agricultural Research Service, 2611 W Lucas St.,

Florence, SC 29501-1242, USA

e-mail: Ken.Stone@ars.usda.gov

B. A. King

USDA-Agricultural Research Service, 3793 North 3600 East,

Kimberly, ID 83341, USA

e-mail: Brad.King@ars.usda.gov eliminating irrigation and chemigation on non-cropped areas of a field or for land application of liquid agricultural and municipal wastes. Various aspects of SS-VRI technologies for general crop production are beginning to slowly gain widespread acceptance; however, their uses are largely focused on addressing symptoms of poor design and suboptimal water and nutrient management. Although currently underutilized, SS-VRI technology has the potential to positively impact crop water productivity, water and energy conservation, and the environment. There are also few economic incentives to motivate growers to move to higher levels of SS-VRI management. Greater adoption rates will likely require higher costs for water and energy, severely restricted water diversions on a broad scale, and enforcement of compliance with environmental and other regulations. Sustainable use of SS-VRI will require strong research support, which is currently limited. In the short term, adoption of SS-VRI technologies will be enhanced by addressing equipment deficiencies and research developing basic criteria and systems for defining management zones and locations of various sensor systems for both arid and humid regions. Training adequate personnel to help write site-specific variable rate irrigation prescriptions in humid and arid areas to assist growers with the decision-making process is also a high priority. There is also a large need to educate government boards and bankers on the potential benefits of these systems. The long-term challenges will be to demonstrate that SS-VRI will improve water management or increase net returns. There is a critical need to develop fully integrated management systems with supporting elements that accurately and inexpensively define dynamic management zones, sense within-field variability in real time, and then adaptively control site-specific variable rate water applications, which will be challenging as significant knowledge gaps exist. 


\section{Introduction}

As the major consumer of the world's water resources, irrigation accounts for about four-fifths of the total freshwater consumed and about two-thirds of the total diverted for human uses (Postel 1999). Irrigated lands constitute approximately $17 \%$ of the world's total cultivated farmland but produce $40 \%$ of its food and fiber. Irrigated agricultural activities also provide considerable food source and foraging areas for migratory and local birds as well as other wildlife (Postel 1999; Evans and Sadler 2008; Stone et al. 2010).

Irrigation has shaped the economies of many semiarid and arid areas, permanently coloring the social fabric of numerous regions around the world. It has stabilized rural communities, increased income, and provided many new opportunities for economic advancement. Irrigation permitted human habitation, at times quite dense populations, where it otherwise could not exist. In short, irrigation underpins current society and lifestyles throughout the world. Consequently, irrigation will necessarily continue to be a major part of the world's future agricultural production systems (Postel 1999).

However, major stresses are progressively being imposed on existing water resources around the world due to increasing global population, declining groundwater availability, decreasing water quality, increasing environmental regulations, rising recreational demands, and international and interstate agreements. Rising standards of living in many developing countries with increasing demands for better drinking water and improved sanitation are also driving the world's use of available freshwater supplies, often at the expense of irrigated agriculture. At the same time, arable land degradation is increasing due to salinity, soil erosion, desertification, and the need for additional housing, which are collectively reducing the available land base for production agriculture. Global climate change may further exacerbate the problems through changing temperatures and greater variation in annual precipitation amounts and regional distribution patterns. Water security issues are becoming acute in the USA and elsewhere.

Combining a fully exploited land base with the growing competition for existing freshwater supplies will require that irrigators substantially increase efficiency and productivity per unit of water consumed (Postel 1999; Pereira et al. 2002; Spears 2003; Clemmens and Allen 2005; Khan et al. 2006). Thus, it is to the advantage of everyone to utilize all available tools for resource conservation and reuse their maximum potential to address these major issues.

Precision agriculture (PA) technologies are designed to be able to spatially optimize the use of various inputs for improving or enhancing economic crop production. There are numerous PA technologies, and all have the basic attributes of site-specific treatments to discrete portions of a field through the use of global positioning systems (GPS). They include site-specific aspects of planting, fertilizer application, pest management, and irrigation designed to manage spatial and temporal variability within agricultural fields. Management tools include various types of sensing systems, field sampling, geographic information systems (GIS), wireless communications, on-the-go yield monitoring, and decision support systems.

Recent innovations in low-voltage sensor and wireless radio frequency $(\mathrm{RF})$ data communications combined with advances in Internet technologies offer tremendous opportunities for the development and application of realtime management systems for agriculture. These have enabled implementation of advanced state-of-the-art water conservation measures with self-propelled sprinkler systems such as site-specific variable rate irrigation (SS-VRI) for economically viable, broad-scale crop production with full or limited water supplies. SS-VRI technologies use many of the same management tools as other precision agriculture technologies and make it possible to vary water and agrochemical (chemigation) applications to meet the specific needs of a crop in each unique zone within a field.

Even though advanced SS-VRI technology has been commercially available for center pivots for several years, its adoption by producers has been at very low levels. However, increasingly limited water supplies for irrigation and environmental issues around the world are driving renewed interest in SS-VRI by growers and policy makers and their use has grown in the past few years. For example, conditions in the declining Ogallala Aquifer areas in the central and southern High Plains or in portions of the Platte River Valley in central Nebraska where pumping restrictions and higher costs are rapidly changing irrigators' attitudes and investments toward advanced irrigation water management practices. It is expected that these types of regulatory requirements and other constraints will increase substantially and that they will serve to provide sufficient economic incentives to cause the market share of SS-VRI systems to increase substantially in the future.

This paper defines advanced SS-VRI technologies for center pivot and linear move sprinkler systems and provides an historical overview of the commercial evolution of self-propelled SS-VRI technology (zone control) and some of the barriers to adoption. The discussion is mostly directed toward center pivots rather than linear move systems because center pivots comprise about $99 \%$ of the self-propelled sprinkler market. Various short-term and some long-term research needs are suggested in order to develop markets for these advanced irrigation technologies for general crop production and to conserve water and 
other resources. It is estimated that about $95 \%$ of all the SS-VRI sprinkler irrigation systems in the world are in the USA with Australia, New Zealand, and South Africa accounting for most of the remaining installations. Thus, most of this discussion addresses the American experience.

\section{Site-specific variable rate sprinkler irrigation}

SS-VRI can be defined as the ability to spatially vary water application depths across a field to address specific soil, crop, and/or other conditions. It is included in the spectrum of precision agriculture technologies because advanced SS-VRI methods can potentially impose treatments in ways that optimize plant responses for each unit of water applied in different areas of the same field. It can also include site-specific applications of water-soluble agrochemicals including fertilizers.

SS-VRI has its roots in the control of end guns, angular control of start and stop points, and sequencing sprinkler heads on center pivot corner-arm systems. The ability to stop or start machines at any location in the field is referred to as angular start-stop or "stop-in-slot." This dates back to the use of mechanical linkages in the early days of waterdrive center pivot development. This is still an option, but is now done electronically.

Self-propelled center pivot and linear move sprinkler irrigation systems are particularly amenable to site-specific approaches because of their current levels of automation and large area coverage with a single lateral pipe. The definition of sprinklers in these applications includes the use of LEPA, bubblers, sprayers, spinners, and other related spray techniques to apply water. These devices are usually on drop tubes in or just above the crop canopy. Impact-type sprinklers are generally not included because the methods used to vary applied depths of water (e.g., pulse modulation) on commercial systems are not compatible in practice.

\section{Types of SS-VRI sprinkler irrigation systems}

Center pivot and linear move sprinkler systems are designed and generally operated so as to replace the average water used by the crop over the past few days as uniformly as possible across the field. Irrigations are frequent and apply relatively low amounts of water, so that soil water is ideally maintained at relatively constant levels. The high frequency of the irrigations under these machines potentially reduces the magnitude of variability in soil water content in the field. However, stochastic spatial and temporal variability of a number of other interrelated factors (e.g., variations in soil properties, topography, runoff, within-field runoff (also called runon), pests, tillage, fertilization, uneven incident precipitation and hail, pesticide carryover effects, and herbicide drift from adjacent fields) across a field can still affect crop growth during the growing season and from one season to the next. These factors can influence management decisions over time, which may also introduce additional infield variability to crop production. Consequently, the center pivot industry is beginning to market irrigation systems that can adjust for at least some of this spatial and temporal variability, which is typically referred to as sitespecific variable rate irrigation (SS-VRI). Manufacturers are just starting to offer site-specific controls for linear move sprinkler systems. Kranz et al. (2012) has summarized characteristics of some of the various commercial site-specific control systems and panels.

Application rates and base uniformity are primarily established by the sprinkler nozzle package, but the depth of water applied per irrigation with self-propelled center pivots and linear move sprinkler systems is generally controlled by the travel speed of the machine. Center pivot manufactures introduced mechanical control panels in the early 1980s using special tower control boxes and a slowdown timer which effectively controlled machine speed across large areas of the field in $30^{\circ}-180^{\circ}$ sectors. In 1992 , Valmont Industries (Valley, NE, USA) introduced a panel that allowed the operator to program speed changes based on the angle resolver at the pivot point.

In the past few years, some companies began marketing center pivot control panels with an option to change center pivot travel speed in increments ranging from $1^{\circ}$ to $10^{\circ}$ as the machine rotates around the field. This tactic effectively changes application depths in each defined radial sector of the field, and no additional hardware is needed compared to a standard machine (some may need a GPS). This practice is commonly referred to as speed or sector control. It could also be referred to as variable depth irrigation, although some erroneously refer to it as variable rate irrigation. Nevertheless, field variability seldom occurs in long, narrow triangular-shaped parcels, and adjusting machine speed may not always be a sufficient level of control because soil and crop conditions often vary substantially in the radial direction.

Consequently, center pivot manufacturers are also offering site-specific variable rate irrigation systems that can differentially apply water site specifically to irregularly shaped areas or management zones. This is referred to as zone control. Specialized equipment such as control, panels, many valves, supplemental wiring, and a GPS is required to control the irrigation in each management zone. Most zone control SS-VRI systems vary water application depths by various forms of pulse modulation (on-off cycling of spray-type sprinkler heads) for a given machine speed. Valves are located on every sprinkler head or groups 
of heads. Water is then applied to each zone by controlling water output amounts from each group of heads along the length of the machine depending on their location in the field. Zone control has a larger potential for achieving efficient management of water and energy than speed control and is the general focus of this paper.

The most common site-specific sprinkler irrigation systems in use today are speed control systems, and it is anticipated that much of the short-term growth will likely occur with these types of systems. Speed control technologies are probably being used close to their technical capacity to improve water productivity at this time. However, zone control systems can achieve the same effects provided by speed control, but with greater flexibility, and provide more management options.

Saving water or energy has not usually been the highest priority by either zone control or speed control irrigators. However, computer simulation studies comparing conventional and "optimized" advanced site-specific zone control by center pivot irrigation have reported water savings of 0-26\% (Evans and King 2012). However, the water- or energy-saving benefits of zone control SS-VRI have not been independently verified by field-based research. Speed control has also not been scientifically evaluated with simulation models or in the field.

\section{Historical development of SS-VRI}

Many individuals, groups of researchers, and companies have been developing SS-VRI technologies for at least the last 20 years. Almost all of the SS-VRI research done to date has been directed toward development and improvement of hardware and basic zone control software. As a result, several innovative technologies have been developed to variably apply irrigation water to meet anticipated whole field management needs in precision irrigation, primarily with self-propelled center pivot and linear move irrigation systems. These efforts have been reviewed by Buchleiter et al. (2000), Evans et al. (2000, 2012), Sadler et al. (2000), McCarthy et al. (2010), and others.

Researchers at the University of Idaho (UI) filed for a conceptual patent on SS-VRI on December 16, 1991, entitled "Method and apparatus for variable application of irrigation water and chemicals" (McCann and Stark 1993). The UI SS-VRI patent was licensed in 1994 to a start-up company, Precision Irrigation Control Systems of Soda Springs, ID, who later partnered with the JR Simplot Minerals and Chemical Division (Pocatello, ID, USA) to commercialize SS-VRI. Through a USDA, Small Business Innovation Research Grant, they began development and testing of their SS-VRI equipment on two center pivot irrigation systems (one in eastern ID and one in southwestern Wyoming). During this time, the J. R. Simplot
Company applied for and received a patent for a highly integrated site-specific irrigation system with a separate chemigation line and included system-mounted sensors and other enhancements entitled "Closed loop control system, sensing apparatus and fluid application system for a precision irrigation device" (NcNabb 1999). However, shortly afterward, the J. R. Simplot Company decided to discontinue the project and concentrate on core business endeavors. The UI SS-VRI patent was later licensed to FarmScan Ag Pty Ltd (Toowoomba, QLD, Australia).

Recently, a few irrigation system manufacturers have begun offering VRI as an option on new center pivot installations. In 2006, an Australian company (Computronics) began selling the FarmScan SS-VRI controls for center pivots in the USA through a company in southeastern USA (Holder and Hobbs). In 2008, the marketing of Computronics was shifted back to FarmScan. Starting in 2010, Valmont Industries began offering the FarmScan sitespecific variable rate package through their dealer network based on a licensing agreement. Also, based on the licensing agreement, Valmont Industries began developing two different VRI packages for center pivots based on Valmont irrigation control systems. In 2010 Valmont Industries began selling zone control units on a limited basis, which was expanded in 2011 to offer both speed and zone control. FarmScan is now sold as a third-party package in the USA by Advanced Ag Systems, Inc.

Some other center pivot manufacturers and related companies are also beginning to integrate various sitespecific control options with their center pivot sprinkler systems. For example, in about 2009 Lindsay Manufacturing started working with Precision Irrigation of New Zealand and began to offer zone control VRI in some countries. Also in 2009, AgSense (http://www.agsense.net/) began offering speed control as part of their add-on telemetry package. Integrating soil moisture sensing and wireless communications with the remote center pivot monitoring systems to assist in management decisions is also beginning to receive commercial attention by center pivot manufacturers. Several companies have capabilities for variable rate chemical injection into center pivots with varying flow rates caused by end guns or other factors.

A program to extend SS-VRI technology was initiated in 2005 by the University of Georgia to promote SS-VRI in the Flint River Basin using the FarmScan system, which at that time was the only commercially available zone control SS-VRI system. The USDA-NRCS Environmental Quality Incentives Program (EQIP) provided 75-25\% cost-share funding for about 40 systems. Four additional SS-VRI systems were purchased by growers without cost-share assistance. These systems were installed on peanut, cotton, and corn fields plus some turf farms. A companion USDA NRCS Conservation Innovation Grant also provided funds 
to demonstrate the benefits of SS-VRI for irrigation management, water conservation, and optimal application efficiency through a series of workshops and field days as well as some research efforts (Perry and Milton 2007).

In early 2012, it was estimated that over 120 FarmScan VRI systems were installed (Heard 2012) in the United States (mostly in Georgia and Alabama). However, it is estimated that only $25 \%$ or less of these systems are currently using the full features of site-specific irrigation (zone control) for improved crop water management.

In the past several years, various commercial manufacturers of self-propelled sprinkler systems have also been offering limited site-specific capabilities for center pivot and linear move sprinkler systems for tertiary treatment of agricultural processing and municipal wastewaters using soil biota and crop uptake for treatment and disposal. These systems are used to periodically apply water to specified areas within a field based on approved regulatory plans primarily for management of nitrogen, phosphorous, and various potential biological contaminants in the effluent. Economic levels of crop production are generally not a concern. These systems generally have static application maps that often do not change from year to year, and feedback mechanisms often consist of periodic soil water measurements and soil sampling to monitor the levels of various chemical and biological parameters.

A side benefit of the recent surge in the use of SS-VRI technologies is that there has been an increased interest in using other PA technologies such as variable rate seeding and variable rate fertilizer applications in conjunction with their SS-VRI systems. However, the research to support the continued growth of PA technology is generally lacking, especially when used in combination with SS-VRI systems.

\section{Current adoption of SS-VRI technology}

Adoption of SS-VRI by producers has been slow and remains at low levels. To put this in perspective, it is estimated that there are about 175,000 center pivot and linear move sprinkler systems in the USA (USDA, NASS 2009), and it is estimated that less than 200 of these machines currently have SS-VRI capabilities other than speed control, end gun, and corner system controls. It is not known how many of these sprinkler systems are actually using SS-VRI capabilities for zone-controlled crop water management, but it is probably less than 50. It is also estimated that there are less than 500 speed control systems currently in fields around the world, but it is not known how many are being used for site-specific applications.

Current uses of SS-VRI zone control technologies on agricultural fields are generally on a relatively coarse scale. Probably, the most common use is limited to site-specific non-applications of water to complex-shaped, non-cropped areas such as waterways, ponds, roads, drainage ways, or rocky outcrops where some interior sprinkler heads are turned off as the machine moves over these areas. Management objectives tend to involve balancing the frequency of irrigation events with managing water content of various soil types. In some cases, there may be as much as a $30 \%$ difference in applied water between soil types in a single irrigation.

Irrigation equipment dealers have normally tended to focus on potential water-saving benefits of zone control only if the customer has severely limited water supplies. In general, farmers with more abundant water supplies are looking to improve the yields of lighter textured soils while not overwatering the low areas or the heavy soils by applying sufficient amounts of water to each area and reducing run-on.

The use of zone control SS-VRI for general crop production is still quite low and is mostly directed toward adjusting for soil textural differences and treating symptoms such as localized overirrigation, underirrigation, runoff, ponding, limited or declining well capacities, fluctuating water supplies, maintenance issues, nutrient management, and related concerns under maximum evapotranspiration (ET) scenarios. However, the basic underlying problems are still left untreated. This may be partly because adequate technical assistance is limited, and perceived inadequacy of economic benefits, perceived complexity of the technology by growers, and economic or regulatory incentives are generally not sufficient to cause producers to move to higher levels of management. Consequently, SS-VRI systems often do not produce measureable savings in water or energy use. In short, there is little commercial or grower interest at this time for optimization of the technology for maximum water productivity with minimal yield reductions (e.g., managed deficit irrigation), except in a few severely impacted water short areas.

The significant underutilization of zone control SS-VRI technology is likely to be continued into the future until: (1) Cost-effectiveness is increased by higher water and energy costs; (2) regulatory limits on water application amounts are implemented broadly; (3) suitable economic incentives in compliance with environmental and other regulations are implemented and enforced; and (4) information on how to manage these systems with demonstrated increased economic returns is illustrated with compelling regional research results.

\section{SS-VRI state of the art}

In general, continuous, incremental changes, which are largely driven by economic considerations, are the natural progression for a technology to advance to the point where it can be implemented to its full potential. This is the 
process that SS-VRI is currently following, and to graphically illustrate this concept, Fig. 1 conceptually depicts the relative potential (not to scale) of various elements of center pivot technologies and research gaps. This figure shows the general trends for increased water productivity (more yield per drop) with increasing technology adoption and higher management levels with the associated nonlinear rises in marginal costs (change in cost per unit increase in water productivity) and water productivity. The major differences between the different regions in Fig. 1 are mostly related to the level of the control and associated decision support systems. Region D on this figure indicates standard irrigation technology levels, Region C shows the potential contributions of speed control systems, while the combined A, $\mathrm{B}$, and $\mathrm{C}$ regions represent the nonlinear technology gradient possible with zone control systems. It should be noted that many technologies such as distributed sensor systems and managed deficit irrigation can be applied across all control and management levels with varying degrees of effectiveness, but the supporting research is often missing.

Figure 1 essentially illustrates the step-by-step process needed to improve existing irrigation systems and to refine the growers' management skills to levels where they can start to economically implement the spectrum of advanced SS-VRI technologies. Most of the current SS-VRI research is in Region A and the uppermost part of Region B, which is where the cutting-edge research and the primary scientific challenges are to be found. However, the lower third of Region B plus Region C and Region D in Fig. 1 is where the industry and the growers are primarily operating today showing a significant gap in research to meet emerging needs.

Meeting the research needs of the $\mathrm{B}-\mathrm{C}$ regions will be required to encourage the increased adoption of these site-specific irrigation technologies. However, private and public research is currently not meeting the basic, short-term needs of today's markets. Furthermore, at current funding levels, it is unlikely that regional public research, extension, and training will be able to catch up in the next $5-10$ years because the irrigation industry is moving much faster than the research. Thus, the needed research support will probably have to come from the impacted industry, electric utilities, and commodity groups.

\section{Potential barriers to adoption}

As mentioned, adoption of the various PA technologies including SS-VRI has been generally limited, and its use by early adopters has not always been sustained. In addition, research has generally not provided information on how to use the technologies to achieve an economic advantage or to provide sufficient evidence to support claims of expected benefits of many PA technologies. Producers generally perceive a lack of sustainable, consistent economic or agronomic advantages from many of the available PA technologies (Lamb et al. 2008). In addition, the value of ancillary benefits such as reduced environmental impacts and improved information flow has not been well demonstrated or encouraged (Auernhammer 2001).

PA technologies generally address individual components of the cropping system such as fertilizer management, planting, pest management, and harvesting. On the other hand, site-specific water management must utilize a whole-system approach that considers aspects covered by several other PA technologies. Irrigation decisions are repeated multiple times during the season, which is not the case for many other PA technologies. Thus, a potential barrier is that full implementation of advanced SS-VRI generally has the most difficult requirements and the most complicated and costly control systems of all PA technologies, and SS-VRI is also the most expensive in terms of management because of the much higher frequency of
Fig. 1 Conceptual representation of the state of the art and the relative capacity of various elements and supporting technologies of self-propelled sprinkler irrigation technologies to increase water productivity (not to scale)

\begin{tabular}{|c|c|c|c|c|c|}
\hline & $\begin{array}{l}\text { Advanced Site-Specific } \\
\text { Zone Control }\end{array}$ & $\begin{array}{l}\text { Current Site- } \\
\text { Specific Irrigation } \\
\text { Research }\end{array}$ & $\begin{array}{l}\text { Dynamic mapping/real-time feedbach } \\
\text { Adaptive closed-loop control } \\
\text { Integrated decision support }\end{array}$ & & \\
\hline & $\begin{array}{l}\text { Variable Rate Irrigation- } \\
\text { Zone Control }\end{array}$ & & $\begin{array}{l}\text { Distributed sensor systems } \\
\text { Open-loop control } \\
\text { Basic decision support } \\
\text { Simple prescriptions } \\
\text { Static management zones } \\
\text { No irrigation of non-cropped areas }\end{array}$ & & \\
\hline के & Variable Depth Systems & & Speed Control & 艺 & $\stackrel{\tilde{\omega}}{\kappa}$ \\
\hline$\sum_{3}^{\pi}$ & $\begin{array}{l}\text { Standard Center } \\
\text { Pivot Systems }\end{array}$ & $\begin{array}{l}\text { Current and past } \\
\text { research } \\
\text { and general level } \\
\text { of commercial } \\
\text { adoption }\end{array}$ & $\begin{array}{l}\text { Angular start-stop control } \\
\text { Soil water monitoring } \\
\text { End gun control } \\
\text { Optimal cropping systems } \\
\text { Basic irrigation scheduling } \\
\text { Soil water conservation } \\
\text { Design guides }\end{array}$ & 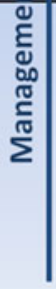 & 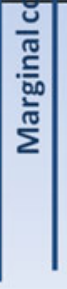 \\
\hline
\end{tabular}


treatments compared to other PA technologies. In general, technical assistance for PA technologies, including SSVRI, is universally quite limited, which is also hindering adoption.

The relatively high capital cost per hectare for the equipment may have also been a deterrent; however, equipment costs are coming down due to technological advances. Growers may have also been reluctant to adopt SS-VRI because, until the past couple of years, the only choices for SS-VRI equipment and controls were thirdparty sources without established support networks. In addition, some of the slow rate of commercial development of SS-VRI may have been due to liability and patent issues limiting availability and promotion.

Obviously, there are tremendous opportunities for expansion of SS-VRI, but there are some significant barriers to the adoption of these technologies. These barriers can only be overcome by more directed private and public research and education programs to regionally address the specific concerns.

\section{Research needs}

As mentioned, there is a pressing need for agriculture to significantly improve the production on less land and using less water. It is to the advantage of all to be able to utilize all available technologies to their maximum potential to address these important water resource issues. Site-specific sprinkler irrigation technologies offer a set of options that could potentially provide significant water and energy savings; however, little research has been done on the economics or the management of SS-VRI sprinkler systems for greatest agronomic or resource conservation benefits. Much additional basic and applied research will be required to give producers the tools they need to fully implement existing site-specific as well as improve more common uniform sprinkler irrigation systems.

"Site-specific" inherently implies that prescriptions for various SS-VRI technologies will be climate, crop, and region specific. Management strategies for humid areas will be much different than approaches to SS-VRI management in arid areas. Humid area SS-VRI management is basically focused on minimizing yield reductions due to the timing and duration of short-term drought that limit yields and accounting for variability of incident rainfall across a field for maximum crop yields (Sadler et al. 2002; Perry and Milton 2007; Bockhold et al. 2011). Thus, irrigations in humid areas often apply less than $20 \%$ of the total crop water use. For fully watered crop production, water savings from site-specific irrigation may be greatest in humid climates by spatially maximizing the use of non-uniform incident precipitation over the growing season. In contrast, arid area management is focused on managing season-long drought stresses using a whole-system approach (Evans and Sadler 2008). Irrigations may supply more than $80 \%$ of total crop water use over the season; however, full water applications for maximum yields are not always an option. Therefore, transferability of SS-VRI research results to different regions will not always be appropriate, and this type of research will have to occur regionally wherever SSVRI is practiced.

Sound decision making involves defining the scale of the problem and how much is to be gained from solving the problem; however, the development of SS-VRI has not followed this process. Almost all of the SS-VRI research done to date has been directed toward development and improvement of hardware and basic control software to implement SS-VRI. The net result of this earlier work is that SS-VRI has essentially become a solution looking for a problem. Unless the problems to be addressed can be precisely defined and quantified for research and education, SS-VRI runs the risk of basically remaining a novelty, and research aimed at developing more advanced SS-VRI technologies will continue to be fragmented and a potential waste of resources.

There are a limited number of site-specific center pivot and linear move sprinkler systems in use by public and private researchers in several states (e.g., GA, KS, MO, MS, MT, ND, SC, TX, and WA). Many have developed their own control systems ranging from manual to fully automatic and installed them on standard machines because appropriate commercial SS-VRI systems were either unavailable or unsuitable for research. Several of these systems are using their site-specific capabilities as tools for new crop variety evaluations and large plot research where water applications are not treatments. Managed deficit irrigation and management of SS-VRI to increase water productivity is receiving little attention. Only a few locations are actively conducting research designed to improve water management and encourage adoption of SS-VRI systems with self-propelled sprinkler irrigation, and much of this is in the early stages.

Limited grower experiences over the past few years with new SS-VRI systems are providing some direction to the manufacturers, but verifying research is lagging. Adoption of the SS-VRI technologies is currently hindered because the short-term and related long-term research needs are receiving little attention from researchers. Advanced zone control management techniques and systems are currently receiving much of the limited research attention, and many of the basic tools required for the SS-VRI industry to flourish are missing. These critical research requirements have both short-term (e.g., $\leq 5$ years) and long-term ( $>5$ years) considerations as well as important technology transfer aspects, which are discussed below. 
Short-term research needs

There are several fruitful, applied research and technology transfer opportunities that are needed to encourage sustained adoption of various elements of SS-VRI. These needs include both commercial development and scientific research by public and private groups that addresses equipment and management issues. It should be emphasized that these short-term needs are only the initial goals of a directed program to develop long-term solutions.

Some specific, identified short-term needs and tools for continued commercial development that will be required for sustained adoption of SS-VRI technologies include the following:

1. A need to address various short-term equipment requirements by the industry.

2. A need to develop guidelines and tools to assist consultants and growers in predefining rule bases or standards for economically defining broad management areas. This information can also be used to define the requirements for the type and level of SS-VRI hardware to be installed in field.

3. A need for new tools that determine how to best locate various combinations of non-mobile sensors for maximum benefit across a management area or field and their use.

4. A need for the development and testing of easy-to-use basic decision support systems for simple site-specific irrigation scheduling scenarios in both humid and arid areas.

5. A need to define and implement specialized training on the hardware, software, and advanced agronomic principles for growers, consultants, dealers, technicians, and other personnel on how to define management areas, write prescriptions and placement of sensor systems, and develop management guidelines.

6. A need to educate local, state, and federal government and financial services organizations on the benefits and capabilities of SS-VRI systems to facilitate greater adoption of these technologies.

The situations discussed above point to urgent shortterm needs to develop basic rules or guidelines and tools for irrigation applications in different zones for both humid and arid regions. Short-term research efforts must transfer the technology for building prescriptions and managing SSVRI systems with advanced training programs. These agronomic and engineering tools would be used by consultants and growers and must allow for grower preferences, pest management issues, and some economic considerations. In the short term, many of these goals (e.g., sensor systems) would also apply to improved management of conventional irrigation systems.
In both the short and long term, there is a big need to begin quantifying possible benefits specifically attributable to SS-VRI, such as water and energy savings, yield increases, and more efficient nitrogen use, and their combined impact on the payback time and net farm gate income. This type of information is mostly anecdotal in the early stages, but must also be verified by difficult and expensive field research to support grower adoption.

\section{Equipment needs}

The lack of appropriate hardware has not generally been a restraining factor with regard to the adoption of SS-VRI and other PA technologies. However, there are some equipment needs that remain to be solved by the industry.

One constraint has been the limited availability of lowcost, reliable variable frequency drives (VFD) for large irrigation pumps to match variable irrigation system demands associated with SS-VRI, especially with multiple irrigation systems using a single pump. In addition, the highly variable flow requirements of zone control SS-VRI systems used for chemigation may also require smaller VFD drives for injection pumps to maintain appropriate chemical concentrations.

Commercially available SS-VRI systems generally rely on some form of pulse modulation to control application depths, and there is an urgent need to explore the performance of various sprinkler packages and how each responds to pulse modulation under zone control and under speed control technologies, which may be different.

Because the use of pulse modulation to control application rates has become the industry standard, another area for improvement is the development of reliable, low-cost valves, solenoids, and pressure regulators that can cycle millions of times before failure. Existing valves and solenoids typically cycle in the range of 250,000-300,000 times before failure rates become too high, and these low levels are unacceptable for SS-VRI uses. In addition, some variable rate application methods may also require more reliable, low-cost flow-modulating sprinkler heads that need to be commercialized as an alternative to pulse modulation. All of these devices also should be easy to troubleshoot and maintain.

It is also possible that sprinkler nozzle packages may have to be different for speed control than for zone control depending on water supplies field conditions, management strategies, and the operational characteristics of the sprinkler devices. These issues will need further research to refine these criteria for SS-VRI uses. Nevertheless, equipment needs are relatively minor and are evolving much more rapidly in comparison with the development of management tools for growers and consultants for the optimal operation of these systems and maximization of benefits. 


\section{Tools for defining management zones}

Growers cannot practically manage or account for all of the many sources of variability and therefore tend to group the most critical parameters into relatively homogeneous management zones within a field such as similar soils, topography, microclimate, harvested yields, pest pressures, or plant response. These zones can also vary depending on the issue being addressed (e.g., irrigation, fertilizer, pests). Growers typically do not change these management zones over the season (static).

Most management zones for speed and zone control technologies are currently based on soil texture differences, various physical features, or a combination of both that are initially determined by the grower working with consultants. These types of management zones tend to remain the same from year to year. Ultimately, however, there will be a shift toward dynamically defining management zones from irrigation to irrigation based on real-time feedback from distributed sensor networks and the implementation of adaptive control of SS-VRI systems.

Application of water with site-specific irrigation systems generally involves some type of variable rate application method in combination with geo-referenced maps or position tables defining the various management zones. Management zones for SS-VRI can be used to treat a whole field or to treat small areas of a field with simple on/off sprinkler controls in single span-wide treatment areas.

Developing static (fixed) prescriptions for no irrigation of non-cropped areas is straightforward and relatively quick. Photographs and maps can be overlaid with a field layout map, and the non-irrigated areas can be easily delineated and used for VRI control. However, developing agronomic management areas is much more complex, and they will vary from year to year because they must be crop specific.

Today, most agronomic management zones are based on static or quasi-static spatial data describing soil and other field properties (e.g., bulk electrical conductivity, soil texture, soil depth, slope, rocky outcrops, waterways, roads, etc.). These data are commonly determined by grid sampling of soils for texture and fertility, GPS mapping of apparent electrical conductivity and other soil parameters, postharvest field data, and other physical or chemical parameters (Pierce and Nowak 1999; Zhang et al. 2002; Camilli et al. 2007). Center pivot irrigators generally prefer to manage SS-VRI on areas of about 5 ha $(\sim 12.5 \mathrm{ac})$ or larger, which generally deal with relatively broad areas that account for topography, major soil texture changes, or physical constraints. However, PA technologies such as variable rate spraying or site-specific planting can be at much smaller scales.

The ability to define management zones varies significantly from manufacturer to manufacturer. One manufacturer of SS-VRI self-propelled sprinkler systems (Valmont) offers the capacity to define up to 5,400 management zones in a single field (averaging about $0.01 \mathrm{ha} /$ zone), which increase in size with radial distance from the pivot. Even though most center pivot irrigators prefer to have less than 10 management zones in a field, the capacity to have a large number of small zones allows for the approximate definition of large zones with relatively complex shapes. Determination of the locations and numbers of management zones are based on various criteria and grower input. However, basic and applied research is needed to provide guidance on how to best define the economic number and size of agronomic management zones for different levels and types of SS-VRI.

Commercially, assistance in defining management zones or management areas and building suitable prescriptions is in its infancy. Companies such as CropMetrics ${ }^{\mathrm{TM}}$ (http:// cropmetrics.com/) have developed and are marketing a basic sets of tools and provide limited agronomic guidance and training to assist growers and consultants in defining static management areas, which are generally based on changes in soil texture or maps of apparent electrical conductivity (as a surrogate to water holding capacity) and topographic features. While a step in the right direction, static management zones based on only one or two parameters are often inadequate for optimal management because many of the other parameters affecting the crop vary independently throughout the season.

\section{Tools for writing basic prescriptions}

Probably, the most critical research needed to encourage adoption of SS-VRI is the development of guidelines and criteria for defining prescriptions for how a SS-VRI system can be used to increase net economic return and achieve environmental and other benefits. A prescription can be defined as a set of instructions for water application to each management zone for each irrigation event or over the season. It should be based on sound agronomic and economic principles. Soil texture-based prescriptions are currently directed toward maintaining appropriate soil water levels in each management zone throughout the growing season.

In the short term, tools (e.g., software) are needed to help consultants and growers write and evaluate basic agronomic, crop-specific prescriptions for various field management zones. These tools must be developed for several crops in different regions. The existing research base is probably sufficient, but needs to be pulled together for these sets of tools. For example, soil-plant-water relations are a fairly mature science in many respects, and its modeling is sufficiently advanced to hypothesize, develop, and evaluate SS-VRI prescriptions. However, past 
computer simulation studies that have attempted to evaluate SS-VRI prescriptions have failed to show conclusive results, and additional field work is certainly needed to support the development of these types of tools (Evans and King 2012).

\section{Tools for optimal placement of various non-mobile sensor systems}

It is not possible to know the exact conditions in all areas of a field in real time. Distributed, infield plant and soil sensors in combination with agro-weather station control are potentially much more accurate than historical and static map-based inputs. Distributed, infield sensor networks with wireless communications can be used to measure climatic, soil water, irrigation application amounts and other types of variability and assist in the development and implementation of optimal site-specific irrigation management strategies. Various estimating procedures in combination with predefined management zones can help account for variability based on real-time feedback from the field.

Sensors with wireless communications can be at fixed locations or mounted on the irrigation system, farm equipment, or other mobile platforms depending on data needs and requirements. The locations of diverse, nonmobile sensors are seasonal decisions because of labor issues; however, guidelines for placement of networks of diverse field-based sensors, the number of sensors, and how they should be used have not been well defined.

Over the past several years, there has been a considerable amount of research on different sensors and sensor systems to monitor and quantify within-field variability in plant water stress, soil water levels, plant nutrition status, percent cover, disease, and several other parameters (Sadler et al. 2002; Peters and Evett 2004, 2008; AndradeSánchez et al. 2007; Kim et al. 2008, 2009; O’Shaughnessy and Evett 2008, 2010a, b; Kim and Evans 2009; McCarthy et al. 2009; and others). However, these sensing and monitoring technologies are seeing little use in on-farm irrigation management. For example, most current operators of center pivot irrigation systems do not use available soil water monitoring technologies, either due to the expense or because of the growers' past experience with poorly performing or uneconomical field sensor systems. In addition, growers may perceive a lack of time to devote to interpreting and utilizing sensor data on a regular basis in their management.

While various types of sensor systems with wireless communications have tremendous potential for real-time management of SS-VRI, the development of algorithms, sensor specifications, and placement criteria and decision support systems for SS-VRI is still in their infancy. This includes development of analysis and methods to easily use feedback from the sensors in the management zones and how to incorporate into the farmer's decision-making tools as well as to validate speed or zone control performance. Ultimately, recommendations on sensor numbers and locations need to be a part of an easy-to-use decision support program.

There is a great need to continue the development and testing of a range of low-cost, non-intrusive sensors for spatially distributed measurement of soil moisture and various crop response indicators for management of sitespecific systems. Time domain reflectometry (TDR) is improving and becoming more cost-effective, but there are still no reliable, inexpensive and easy-to-use electronic soil water sensors that match or exceed the accuracy and repeatability of neutron scattering devices. Innovative development of these and other types of sensors is essential for improved water management, particularly under managed soil water-deficit conditions.

Properly defined static management zones will guide the placement of some sensor systems, but not all. There remains a critical need to develop tools that help define which sensors are needed and to determine how to best locate various combinations of sensors for maximum benefit across a field. The integration of various sensor types that provides measurements at different temporal and spatial scales makes it potentially possible to extend the range of point measurements and more accurately estimate the variability of other sensors and field data sets.

\section{Decision support}

Acquisition of an advanced irrigation technology does not always result in substantial water or energy savings. These state-of-the-art systems also require higher levels of management, which is often lacking due to a lack of time by the operator to devote to this important aspect. Decision support systems can greatly assist growers in this regard. At this time hardware is distinctly separate from any software used for management, which is probably due to legal liability issues; however, it is necessary that these two functions be integrated for the sustainability of SS-VRI. This will require the development and acceptance of "application programming interfaces" or APIs that standardize data protocols between manufacturers of the different components including the various sensor systems and wireless communications.

The spatial and temporal interrelationships of the soilplant-atmosphere-irrigation systems are rightly perceived as complex by growers who are often reluctant or unable to manage at the necessary levels. Thus, there is a big need to simplify the decision support approaches to make complicated management decisions more transparent to the operator. 
Most current irrigation decision support programs (often called scientific irrigation scheduling programs) are designed to address temporal variability in general crop water use. Irrigation timing and application depths for SS-VRI are often based on simple checkbook budgeting procedures based on estimated maximum ET with little input from soil water or other sensors in the field. Feedback to the process is usually made by spot measurements (e.g., soil water) and other data after the operation is completed and adjustments are made to the program for the following irrigation event. This is a good first step, but these procedures need to be extended to include direct sensor feedback on spatial variability into the control system during the irrigation event.

General, broad-based, intuitive, and easily adjusted software (decision support) for implementation of prescriptions for SS-VRI systems is not available for a multitude of crops, climatic conditions, topography, and soil textures. In the short term, development of basic decision support systems should focus on generalized regional-type prescriptions for common crops in both humid and arid areas. These basic decision support programs should include simple feedback systems from distributed sensor networks, so that corrections can be made to VRI irrigation systems and provide real-time status information to the operator evaluations and adjustments. The next step will be to include spatial variability (e.g., management zones) in this process. Meaningful evaluations may also require the use of other precision agriculture technologies such as GPS referenced yield monitoring to be effective.

The aging farm population and retirements are contributing to the rapid trend of increasing farm sizes. Equipment is getting larger and larger, and time for management is in short supply. The lifestyles and decision making of young farmers are highly dependent on new communications technologies and computers. Presently, only basic monitoring and simple irrigation management decisions (e.g., on-off times and application rates) are available for remote access. Consequently, adoption of SS-VRI will require that the irrigation industry develops integrated controls and decision support systems that can be accessed with smart phones and tablet computers.

There is a concurrent need to develop improved, easy-touse decision support systems for site specifically applying crop amendments (e.g., nutrients, pesticides) to improve profit margins and reduce environmental impacts with little additional cost (Watkins et al. 1998; King et al. 2009). These features add value to zone control SS-VRI systems that help offset high initial capital costs and management expenses. In addition, site-specific chemigation adds another layer of complexity to water management.

Logically, decision support will also include the seamless integration of the above-named tools for defining management zones (static or dynamic), automatic means for writing irrigation and chemigation prescriptions, and resolve locations of diverse non-mobile sensor networks. In the short term, scientifically sound solutions to these objectives will have to be developed separately and later integrated though more advanced decision support systems. In addition, their use will have to appear to be relatively simple to encourage sustained adoption.

\section{Technical assistance training for SS-VRI}

Technical assistance needs have many short-term and longterm implications. The increasing complexity of implementing advanced irrigation strategies and other farming activities place even greater demands on management. Adjusting water application depths to account for spatial and temporal variability as well as to fine-tune the water management can be a significant challenge, and most producers will require agronomic and other types of assistance from multiple sources to successfully implement SS-VRI technologies. Thus, there is a critical need for trained personnel, who will often be independent from the equipment dealers, to assist growers in using these tools to write prescriptions, and determine the best locations for sensor stations. However, this is greatly complicated by the acute shortage of available agronomic expertise to set up and maintain decision support software for each field (English 2010).

In general, universities, local colleges, and other institutions are not training individuals with the type and level of expertise needed to service the needs of producers using or wanting to use SS-VRI technologies. Extension and technical transfer programs are also being cut across the nation, and these situations are not expected to change in the near future. This means that growers, dealers, and others will have to answer questions by their own trial-anderror research efforts. Undoubtedly, many of these local solutions will be quite innovative, but the shortage of state irrigation extension, consultants, and other personnel to extend these results and other research will probably reduce adoption rates of SS-VRI in other areas.

Ultimately, the shortage of expertise will be partially addressed by various enhanced decision support programs to fill some of the gaps. However, growers generally do not have the interest, knowledge, or the time to adjust and code software; thus, dealers or consultants would likely have to provide this service.

The need for advanced training for consultants and crop advisors is immediate and continues well into the future. However, training programs may be ineffective until results from the above list of short-term research areas can properly define the scope and criteria for the training curricula, and sufficient numbers of people are being trained. Plans are 
being considered to produce this information, but much of these results may not be available for several years, which may further hinder the progress of SS-VRI adoption.

\section{Educating funding organizations}

An additional reason for non-adoption is that some government regulatory and action agencies such as the USEPA, USDA boards, and financial institutions generally do not support SS-VRI technologies for funding and costshare programs, especially at the local level. The lack of awareness of benefits may be partially due to a lack of understanding of the technology and a shortage of regional research demonstrating a return on investment. In addition, manufacturers' distribution networks and dealers are sometimes cautious to embrace new technologies until they see opportunities for profit and have the resources and training to support the product. Thus, a concerted effort is needed by government and university researchers to provide information and materials that explain the potential benefits as well as problems of SS-VRI to policy makers and regulatory agencies at local, state, and federal levels.

\section{Long-term research needs}

One of the major reasons attributed to the current low adoption rates of SS-VRI has been the shortage of research by public and private groups, demonstrating that this technology will better manage water and/or increase net returns. Documented and proven water conservation strategies using site-specific sprinkler irrigation for crop production are quite limited and need to be demonstrated regionally. In addition, past zone control SS-VRI agronomic research was generally directed toward meeting full crop ET and maximizing yields per unit area with little concern for limited water availability scenarios (e.g., managed deficit irrigation), which is becoming the norm in many areas. These long-term research programs should be implemented now, so that they are ready when needed.

There has been a large amount of work done on management of deficit irrigations for perennial, high-value horticultural crops under microirrigation systems, but relatively little has been done with annual field crops (e.g., corn, cotton, sorghum) under center pivots. Scattered large plots (quasi-zone) management studies have been conducted in a few areas since the 1990s on deficit irrigation strategies for some field crops, but almost none under SS-VRI equipment. It should be possible to utilize this information for zone control SS-VRI on a regional basis, but this research has not yet occurred.

Likewise, there has been no research to optimize the use of self-propelled site-specific sprinkler irrigation in combination with other precision (site-specific) agriculture technologies (including site-specific aspects of planting such as auto-row shutoff and variable rate seeding, and variable rate herbicide and fertilizer applications), which will be critical in establishing the long-term, regional costeffectiveness of these systems for general crop production.

Advanced zone control irrigation practices and strategies will ultimately utilize highly developed integrated control and decision support systems. Future advanced SS-VRI will rely heavily on advanced sensor and communications technologies, computer models, fixed and mobile sensor platforms, and GPS that are integrated through the application of various integrated plant and systems models to analyze intensive data sets in a GIS (geographic information system) environment. These inputs can potentially be utilized to dynamically implement real-time site-specific water applications to account for temporal and spatial variability throughout the growing season by the use of various integrated control systems, sensor networks, and decision support strategies (e.g., Evans et al. 2000, 2012; O'Shaughnessy and Evett 2008; McCarthy et al. 2009, 2010 and others).

Long-term SS-VRI research will have to build on these technologies to develop integrated, holistic, real-time decision support systems that are able to integrate data from a variety of sources to optimize water applications that accurately account for spatial and temporal variations in plant responses in real time. But, the complexity in optimizing multi-objective, multivariate "prescriptions" for dynamically changing management zones will be a substantial challenge for researchers, industry, and growers alike (Crespo et al. 2010).

\section{Water production functions for management}

Inherent in efforts to reduce seasonal crop water use is the need to optimize effective rainfall, improve application timing, employ some aspects of managed deficit irrigation, and maximize crop production or income per unit of applied water. Irrigation management strategies that reduce actual crop water use with minimal yield losses (e.g., management to increase crop water productivity) will require better information on crop water use and yield potentials under stressed conditions.

More than 50 years of research has been conducted to enable prediction of water requirements for fully watered crops that are actively growing free of pest or nutrient stress (maximum ET). But, little is known about how pest or nutrient stress affects water requirements or how ET varies under various deficit irrigation management scenarios. Likewise, how evapotranspiration varies with yield potential is unknown for most crops. Crop water use is a combination of soil evaporation and plant transpiration. Stresses that inhibit plant development would be expected to 
decrease transpiration due to a reduction in leaf area, but soil evaporation will likely increase due to more solar radiation reaching the soil surface. Furthermore, water requirements for a fully watered crop under pest or nutrient stress may not change in direct proportion to yield potential.

Answers to many of these questions will require the development of water production functions for various annual and perennial crops in humid and arid regions. Water production functions are generally defined as the relationship between yield and water applied (or ET). Knowledge of these crop-specific relationships is necessary when operating irrigation systems for less than maximum ET conditions. At the field level (not individual plants), these production functions include the inherent spatial variability of soils, salinity, pests, fertility, and water application uniformity at different irrigation levels in different locations. Improved genetics that increase physiological water productivity such as drought resistance that improves yields may cause these curves to shift, which will require new efforts to redefine these relationships. The slope of these functions at a point is referred to as crop water productivity (also called water use efficiency).

Maintaining or increasing crop productivity while reducing the amount of applied water implies that producers will often be managing irrigations under severe to moderate soil water-deficit conditions (i.e., managed drought) in either time or space during at least part of the growing season. This is often referred to as managed deficit irrigation, which can have many forms and generally serves to increase crop water productivity. Managed deficit irrigation strategies have the potential to conserve more water with less impact on yields than any other alternatives when implemented correctly (Bras and Cordova 1981; English et al. 1990, 2002; Zhang 2003; Fereres and Soriano 2006; Evans and Sadler 2008; Geerts and Raes 2009; Rodrigues and Pereira 2009). It is possible that SS-VRI could play a role in managed deficit irrigation of field crops when there is significant variability in soils and topography. Another case where SS-VRI might be an important management alternative would be when sitespecific planting of different varieties or variable planting densities across a field to match specific predetermined conditions that would introduce additional artificial variability. A considerable amount of research has been conducted on managed deficit irrigation on many crops with microirrigation, but its application to the management of SSVRI with center pivot systems where optimal conservation benefits should be attainable is just starting.

\section{Integrated sensor systems}

Past SS-VRI research and industry efforts have mostly focused on the irrigation equipment, but this has produced a very incomplete picture of the technology. Notably absent has been the development of low-cost, reliable, and accurate field-based sensing systems as well as the feedback and control systems to use those sensor systems (Andrade-Sánchez et al. 2007; Kim et al. 2008, 2009; O'Shaughnessy and Evett 2008; McCarthy et al. 2009, 2012).

The maximum benefit from a site-specific variable rate irrigation system will ultimately be realized when indicators of plant health (e.g., soil water levels, plant stress indicators) in each management area are monitored to improve the simulation output of integrated computer models. The ongoing "time-temperature-threshold" research with infrared thermocouple sensors to monitor biotic and abiotic plant stresses is a step in the right direction (O'Shaughnessy and Evett 2010a, b), but much more is needed in this regard. Adaptive control of future SS-VRI systems will likely require networks of diverse sensors with wireless communications at variable densities.

Automated on-the-go mapping of plant stress as part of the decision support process will allow for timely intervention and mitigation of the problem before critical thresholds are exceeded. Research is currently underway to develop dynamic management systems for SS-VRI based on real-time data from remote and local sensors mounted on the center pivot irrigation system (e.g., Peters and Evett 2008; O'Shaughnessy and Evett 2010a, b; McCarthy et al. 2010; Bockhold et al. 2011), but much more needs to be done.

\section{Advanced decision support systems}

Conventional approaches to irrigation management may not be applicable to real-time management of SS-VRI because of the complex spatial and temporal interactions among the physical and biological components. Future sitespecific irrigation strategies must be guided by integrated decision support systems that utilize various computer models (actual ET, crop growth, pest development, irrigation system, etc.), sensor systems, and other input to optimally determine when and where to irrigate and how much water to apply at every location in the field. Making all the tools work together seamlessly is often referred to as interoperability by people working in advanced control systems.

It will be necessary to write prescriptions automatically in real time in response to data from a wide variety of distributed sensor systems and other input. Predictive modeling approaches will prove valuable in interfacing with crop and pest models and other software tools, field data networks, wireless communications, and other remotely sensed data for automated decision making. The various components of these decision-making programs should also have some abilities to be self-calibrating and 
self-learning, so that they can automatically adjust to changing conditions from sensor systems in real time. Integration of these considerations and factors into the irrigation decision-making process can determine when, where, and how much water to apply in real time, which enables implementation of advanced state-of-the-art water conservation measures for economically viable production with limited water supplies. The next-generation decision support systems must also be integrated with other precision (site-specific) agriculture technologies for maximum benefit.

Future decision support systems for SS-VRI must generally address the causes of variability, assess the irrigation system capabilities needed to achieve the desired management level, determine constraints inherent in the existing equipment, and consider the philosophy of the owner/ operator to optimize water applications that accurately account for spatial and temporal variations in plant responses (McCarthy et al. 2012). Ultimately, these decision support systems must also be able to optimize physical, agronomic, and economic constraints at the management zone, field, and whole farm levels that also consider yield potentials, crop, and water prices in order to maximize net return rather than total yield as currently practiced (McCarthy et al. 2010). It is highly likely that, for better or worse, these advanced decision support programs will be developed commercially without the guidance of supporting research.

\section{Economics of crop production using SS-VRI}

Higher net returns to the grower may be needed to economically justify the capital costs of implementing sitespecific zone control irrigation management with center pivots (about $\$ 200-\$ 550 \mathrm{ha}^{-1}$ additional cost depending on size and options), plus basic soil mapping (commonly about \$15-\$20 ha ${ }^{-1}$ depending on the type and scale) and management costs. Reliable estimates of ongoing maintenance costs for SS-VRI are not known because of the low adoption rates and relatively short history. Operating costs will probably be higher because of added maintenance of sensors stations, communications, software maintenance, and consultant fees.

Recent anecdotal information from growers on fields with rolling topography using speed control (\$25$\$ 125 \mathrm{ha}^{-1}$, depending on the system) indicates they believe that payback for these VRI systems can be achieved in as little as 1 year due to the ability to reduce runoff. Those using zone control SS-VRI attribute the observed benefits to a significant reduction in yield variability and higher overall productivity, which are largely due to minimizing areas of overirrigation and the associated reductions in runoff. These practices also reduced leaching and soil erosion, and reduced yield variability was often likely to be more of a response to uniform access of applied fertilizers than to water. In non-limiting water situations, savings in water or energy use have not been generally observed nor cited as a benefit by growers using various SS-VRI technologies. These economic and environmental benefits have not been independently verified by scientists across different regions.

Intuitively, the economic benefits of SS-VRI should be obvious. It seems that if economic benefits of higher levels of SS-VRI (i.e., Region A in Fig. 1) exist, they should be easily defined and quantified, but this has not been the case. The use of SS-VRI to avoid irrigating non-cropped areas will clearly be economical in terms of water and nutrient savings as well as avoidance of environmental and regulatory penalties. However, in more than 20 years of public and private research pertaining to SS-VRI, demonstrated proof of any economic benefits for agronomic production has failed to materialize. Much of this is probably because the marginal costs for relatively small water savings (e.g., 5-15\%) are relatively high, which often makes purchasing and managing SS-VRI for maximum profit difficult to justify economically and the impacts difficult to measure. In addition, the magnitude of the variability from the other sources of variability across a field may be masking the ability to make economic or agronomic evaluations. On the other hand, lower management costs for basic treatment of the symptoms of localized overirrigation, underirrigation, runoff, ponding, fluctuating water supplies, etc., make it much easier to justify the expense of a SS-VRI system, but defining any benefits solely due to SS-VRI is still difficult.

As is the case for most of PA technologies, SS-VRI is potentially able to economically optimize a particular management strategy: to get the last 5-10\% reduction of an input with minimal impact on the output. It is basically the final stage of the irrigation optimization process. However, producers and their bankers have difficulty in rationalizing the substantial equipment and management costs associated with relatively small incremental improvements in energy or water savings at current prices. For example, a basic deficit irrigation strategy will probably achieve 90-95\% of the expected goal in reducing water delivery amounts by itself, and the addition of a SS-VRI system and high-level decision support may not be economically feasible for the relatively small gain.

Models and strategies for optimal economic management for optimal net returns rather than maximum total returns for SS-VRI systems should be a long-term goal. Appropriate guidelines for economical management of SS-VRI systems that quantify the monetary value of various management alternatives have not been formulated at any scale, which will be needed to educate policy makers and action agencies. Likewise, little research has been done 
on the economics of the number of zones or sectors for management of these systems for the greatest agronomic benefit.

\section{Conclusions}

The potential to save water at the farm scale depends on the capabilities of the irrigation system and the commitment of the operator to implement water-saving practices and technologies. Conventional irrigation technologies are well advanced and would conserve large amounts of water if implemented to the full extent of their capabilities. Adoption of site-specific technologies could potentially extend these water savings even more. Site-specific irrigation could also play a major role in maximizing net returns when implementing limited or deficit irrigation strategies in water short areas and in the optimal use of precipitation in humid regions. However, conservation of water, energy, and other resources is not typically a high priority in the USA, except in severely restricted areas such as the depleted Ogallala Aquifer regions of the central and southern High Plains.

Advances in technologies including computers, electronics, wireless communications, GIS, and GPS have provided the components necessary for SS-VRI management of self-propelled irrigation systems to move to higher levels. There have been over 20 years of government and private research on SS-VRI, and the technology has been generally commercially available since about 2005 .

However, adoption rates of SS-VRI have been quite low for a number of reasons. Almost all of the SS-VRI research done to date has been directed toward development and improvement of hardware and basic control software with little emphasis on sensing and integrated control. The potential economic and water conservation benefits of these advanced systems have not been independently defined and quantified. Little research has been done on the economics, determination of the number and size of zones or sectors, or the management of these systems for greatest agronomic or resource conservation benefits. In addition, there are few economic incentives at this time for optimization of advanced SS-VRI technology for maximum crop water productivity with minimum yield reductions (e.g., managed deficit irrigation), which is where the greatest conservation potentials can be realized and the greatest research challenges lie. There is a critical deficiency in government extension services providing relevant information on various technologies, which by itself may also be a barrier to adoption of many advanced technologies in agriculture, such as SS-VRI.

Relatively limited work has been done on developing suitable field sensor systems and integrating sensor feedback with the control and evaluation efforts. Furthermore,
SS-VRI systems have been generally evaluated and tested under conditions designed to meet full crop ET and maximize yields per unit area with little concern for limited water availability scenarios. Thus, in many ways, the current state of the technology is a solution looking for a problem. A major hindrance to research has been the lack of coordination and that there has not been a unified clear definition of the problems to be addressed and the value to be derived from the research.

Current uses of SS-VRI technologies for agricultural fields are generally on a fairly coarse scale and are often limited to site-specific treatment of non-cropped areas. Their use for general crop production is still quite limited, and they are basically used to remediate conditions due to poor design, overirrigation, underirrigation, runoff, erroneous irrigation scheduling, in-season precipitation harvesting, inadequate or fluctuating water supplies, or inefficiencies associated with particular crop production practices. Management is typically directed at meeting maximum ET conditions. Treating symptoms rather than the source of a problem may reduce diversions to a field, but not reduce actual seasonal crop ET.

The use of SS-VRI is currently a classic case of technological overkill where users are generally substituting technology for management, which can produce many positive results from the grower's standpoint including higher yields. Management solutions under these conditions are relatively simple and straightforward compared to full utilization of advanced SS-VRI (e.g., Region "A" in Fig. 1). Thus, meaningful reductions in crop water or energy use are not being realized even though the ability of today's SS-VRI technologies to implement advanced management strategies to increase water productivity (economic yield per unit of water) is considerably higher than presently used.

Supporting research on SS-VRI is well behind where the industry and growers are currently moving with this technology. Substantial research and extension efforts are needed to develop tools, training, and education programs to support current SS-VRI management goals and uses in both the short term and long term. These research activities must be regional because the strategies and procedures for humid and arid climates will be quite different.

In the short term, several equipment and research deficiencies need to be addressed to encourage further adoption. Equipment issues include the use of variable frequency pump motor controls for both irrigation and chemigation, and more reliable valves to control individual sprinkler heads. From a research standpoint, the foremost need is the development of guidelines and tools to assist consultants and growers in predefining standards for economically defining sizes and numbers management areas and writing basic prescriptions. It is important that prescription writing 
and updating capabilities be as good as possible so as to not hinder future adoption of SS-VRI technologies. Secondly, there is a need to develop tools that determine how to best locate various combinations of sensors for maximum benefit across a field and their use in management. Thirdly, there is a critical need for the development and testing of easy-to-use basic, generalized decision support systems for SS-VRI starting with simple static scenarios for both humid and arid areas. There is little commercial interest at this time for the optimization of the technology for maximum water productivity with minimum yield reductions (e.g., managed deficit irrigation). The changing demographics of the farming industry will also require much greater reliance on the latest communications technologies such as smart phones in the control and management of these systems.

In addition, specialized, continual training on the hardware, software, and advanced agronomic principles is needed now for growers, consultants, dealers, technicians, and other personnel on how to define management zones (areas), write prescriptions, and develop seasonal crop irrigation management guidelines. This has been slowed because the criteria for training individuals to develop management zones, write appropriate crop-specific prescriptions, and assist with the decision-making processes have yet to be defined. In addition, there is a need for educating bankers and local, state, federal, and other decision makers that fund SS-VRI systems.

Long-term research needs are basically extensions of the short-term research objectives. One long-term hindrance is the lack of general holistic decision support systems, which include the amount of water to apply based on seasonal timing, yield potential, crop and water prices, and other factors at the whole farm scale in order to maximize net return rather than total yield as currently practiced. Work on sensors and sensor systems for management of SS-VRI is still mostly in the research phases and has not progressed to point of general use by growers. Basic long-term research will be needed to develop holistic, integrated decision support systems. However, development of suitable decision-making tools must consider that their potential complexity may also present barriers, which must also be addressed before farmers will use them.

The underutilization of SS-VRI technology is likely to continue until its cost-effectiveness can be increased, which will be the result of several external factors and the lack of advanced management tools. Ultimately, it is expected that higher costs for irrigation water, water scarcity, and the implementation of economic incentives for compliance with environmental and other regulations will potentially provide the necessary incentives for much greater adoption of various advanced irrigation technologies. However, this must be supported by basic short-term and long-term research demonstrating how and the extent that net economic returns can be increased using both conventional and SS-VRI systems. It should be noted that research on advanced SS-VRI irrigation management strategies, sensor systems, adaptive controls, and integrated decision support would likely improve our capacity to better manage conventional sprinkler irrigation systems.

Various forms or aspects of SS-VRI are becoming commonly available and will probably continue their slow rate of growth for some time. A side benefit is that these marketing efforts are helping growers consider their future and how to position their farming operations including center pivot irrigation to take advantage of the many rapid changes in technology. However, the research effort needed to successfully and economically apply the various SS-VRI technologies is substantial and will take several decades to address. With adequate funding, such field research will likely take 5-10 years to obtain measureable results. Maintaining the current levels of inadequate funding for field research on SS-VRI technology means that the time table to accomplish these goals will be substantially increased.

There are many compelling reasons to develop highlevel SS-VRI systems and the necessary adaptive control and management systems. However, suitable research, extension, and education programs to adequately address the barriers to adoption and to practically achieve the potential benefits of SS-VRI will require considerable investment in these areas at a time the nation is attempting to reduce spending on domestic programs, such as public agricultural research and extension programs. This means that bulk of research and education funding will have to come from SS-VRI equipment manufacturers, water districts, electric utility providers, commodity groups, and other interested groups. Unfortunately, much of the necessary work to enhance adoption of SS-VRI technologies will not be done because of its long-term nature, which is seldom funded by non-governmental sources.

\section{References}

Andrade-Sánchez P, Pierce FJ, Elliott TV (2007) Performance assessment of wireless sensor networks in agricultural settings. ASABE Tech. Paper No. 073076. ASABE, St. Joseph, MI

Auernhammer H (2001) Precision farming-the environmental challenge. Comput Electron Agric 30(1):31-43

Bockhold DL, Thompson AL, Suddeth KA, Henggeler JC (2011) Irrigation scheduling based on crop canopy temperature for humid environments. Trans ASABE 54(6):2021-2038

Bras RL, Cordova JR (1981) Intraseasonal water allocation in deficit irrigation. Water Resour Res 17(4):866-874

Buchleiter GW, Camp C, Evans RG, King BA (2000) Technologies for variable water application with sprinklers In: Evans RG, Benham BL, Trooien TP (eds) Proceedings of the 4th decennial national irrigation symposium, ASABE, St. Joseph, MI, pp 316-321 
Camilli A, Cugnasca CE, Saraiva AM, Hirakawa AR, Correa PLP (2007) From wireless sensors to field mapping: anatomy of an application for precision agriculture. Comput Electron Agric 58(1):25-36

Clemmens A, Allen R (2005) Impact of agricultural water conservation on water availability. In: Proceedings of world water and environmental resources congress, ASCE, Reston, VA

Crespo O, Bergez JE, Garcia F (2010) Multiobjective optimization subject to uncertainty: application to irrigate strategy management. Comput Electron Agric 74(1):145-154

English MJ (2010) A developing crisis in irrigation advisory services. In: Dukes M (ed) Proceedings of the 5th decennial national irrigation symposium, ASABE Tech. Paper No. IRR10-9595. ASABE, St. Joseph, MI

English MJ, Musick JT, Murty VVN (1990) Deficit irrigation. In: Hoffman GJ, Howell TA, Solomon KH (eds) Management of farm irrigation systems. ASABE, St. Joseph, MI, pp 631-663

English MJ, Solomon KH, Hoffman GJ (2002) A paradigm shift in irrigation management. J Irrig Drain Eng 128(5):267-277

Evans RG, King BA (2012) Site-specific sprinkler irrigation in a water limited future. Trans ASABE 55(2):493-504

Evans RG, Sadler EJ (2008) Methods and technologies to improve efficiency of water use. Water Resour Res 44, W00E04. doi: 10.1029/2007WR006200

Evans RG, Buchleiter GW, Sadler EJ, King BA, Harting GB (2000) Controls for precision irrigation with self-propelled systems. In: Evans RG, Benham BL, Trooien TP (eds) Proceedings of the 4th decennial national irrigation symposium, ASAE, St. Joseph, MI, pp 322-331

Evans RG, Iversen WM, Kim Y (2012) Integrated decision support, sensor networks and adaptive control for wireless site-specific sprinkler irrigation. Appl Eng Agric 28(3):377-387

Fereres E, Soriano A (2006) Deficit irrigation for reducing agricultural water use. J Exp Bot 58(2):147-159

Geerts S, Raes D (2009) Deficit irrigation as an on-farm strategy to maximize crop water productivity in dry areas. Agric Water Manag 96(9):1275-1284

Heard R (2012) Personal communication. Advanced Ag Systems Inc. Dothan, AL

Khan S, Tariq R, Yuanlai C, Blackwell J (2006) Can irrigation be sustainable? Agric Water Manag 80(2006):87-99

Kim Y, Evans RG (2009) Software design for wireless sensor-based site-specific irrigation. Comput Electron Agric 66(2):159-165

Kim Y, Evans RG, Iversen WM (2008) Remote sensing and control of an irrigation system using a wireless sensor network. IEEE Trans Instrum Meas 57(7):1379-1387

Kim Y, Evans RG, Iversen WM (2009) Evaluation of closed-loop site-specific irrigation with wireless sensor network. J Irrig Drain Eng 135(1):25-31

King BA, Wall RW, Karsky TF (2009) Center-pivot irrigation system for independent site-specific management of water and chemical applications. Appl Eng Agric 25(2):187-198

Kranz WL, Evans RG, Lamm FR, O'Shaughnessy SA, Peters RT (2012) A review of mechanical move sprinkler irrigation control and automation technologies. Appl Eng Agric 28(3):389-397

Lamb DW, Frazier P, Adams P (2008) Improving pathways to adoption: putting the P's in precision agriculture. Comput Electron Agric 61:4-9

McCann IR, Stark JC (1993) Method and apparatus for variable application of irrigation water and chemicals. U.S. Patent No. 5,246,164. September 21, 1993

McCarthy AC, Hancock NH, Raine SR (2009) Automated internode length measurement of cotton plants under field conditions. Trans ASABE 52(6):2093-2103

McCarthy AC, Hancock NH, Raine SR (2010) VARIwise: a generalpurpose adaptive control simulation framework for spatially and temporally varied irrigation at sub-field scale. Comput Electron Agric 70(1):117-128

McCarthy AC, Hancock NH, Raine SR (2012) Advanced process control of irrigation: the current state and an analysis to aid future development. Irrigation Science. doi:10.1007/s00271-0110313-1. Online First ${ }^{\mathrm{TM}}, 8$ December 2011 (in press)

NcNabb GJ (1999) Closed loop control system, sensing apparatus and fluid application system for a precision irrigation device. US Patent No. 5,927,603. July 27, 1999

O'Shaughnessy SA, Evett SR (2008) Integration of wireless sensor networks into moving irrigation systems for automatic irrigation scheduling. In: Proceedings of the 2008 ASABE annual international meeting, ASABE Tech. Paper No.083452. St. Joseph, MI: ASABE

O'Shaughnessy SA, Evett SR (2010a) Canopy temperature based system effectively schedules and controls center pivot irrigation of cotton. Agric Water Manag 97:1310-1316

O'Shaughnessy SA, Evett SR (2010b) Developing wireless sensor networks for monitoring crop canopy temperature using a moving sprinkler system as a platform. Appl Eng Agric 26(2):331-341

Pereira LS, Cordery I, Acovides I (2002) Coping with water scarcity. UNESCO, IHP-VI, 406 Technical Documents in Hydrology, No. 58, Paris

Perry CD, Milton AW (2007) Variable-rate irrigation: concept to commercialization. In Proceedings of the 29th southern conservation agricultural systems conference, June 25-27, Quincy, FL

Peters RT, Evett SR (2004) Modeling diurnal canopy temperature dynamics using one-time-of-day measurements and a reference temperature curve. Agron J 96(6):1553-1561

Peters RT, Evett SR (2008) Automation of a center pivot using the temperature-time threshold method of irrigation scheduling. J Irrig Drain Eng 134(1):286-291

Pierce FJ, Nowak P (1999) Aspects of precision farming. Adv Agron 67:1-85

Postel S (1999) Pillar of sand: can the irrigation miracle last? Worldwatch Books, W. W. Norton \& Co, New York, $312 \mathrm{p}$

Rodrigues GC, Pereira LS (2009) Assessing economic impacts of deficit irrigation as related to water productivity and water costs. Biosyst Eng 103(4):536-551

Sadler EJ, Evans RG, Buchleiter GW, King BA, Camp CR (2000) Site-specific irrigation management and control. In Evans RG, Benham BL, Trooien TP (eds) Proceedings of the 4th decennial national irrigation symposium, ASAE, St. Joseph, MI, pp 304315

Sadler EJ, Camp CR, Evans DE, Millen JA (2002) Spatial variation of corn response to irrigation. Trans ASAE 45(6):1869-1881

Spears TD (2003) Irrigating efficiently to feed the world in 2050. In: Proceedings of the 2003 irrigation association international exposition and technical conference, The Irrigation Association, Falls Church, VA, pp 411-422. CDROM

Stone KC, Hunt RG, Cantrell KB, Ro KS (2010) The potential impacts of biomass feedstock production on water resource availability. Bioresour Technol 101(6):2014-2025

USDA, National Agricultural Statistic Service (NASS), Census of Agriculture (2009) 2008 Farm and Ranch Irrigation Survey. Table 4

Watkins KB, Lu YC, Huang WY (1998) Economic and environmental feasibility of variable-rate nitrogen fertilizer application with carry-over effects. J Agric Res Econ 23(2):401-426

Zhang H (2003) Improving water productivity through deficit irrigation: examples from Syria, the North China Plain, and Oregon USA, Chapter 19. In: Kijne JW, Barker R, Molden D (eds) Water productivity in agriculture: limits and opportunities for improvement. CABI, Wallingford, pp 301-309

Zhang N, Wang M, Wang N (2002) Precision agriculture-a worldwide overview. Comput Electron Agric 36:113-132 